\title{
ATUAÇÃO NA ONCOLOGIA PEDIÁTRICA E A MÚSICA COMO PROMOTORA DE SAÚDE: SIGNIFICADOS PARA OS PROFISSIONAIS
}

\section{PERFORMANCE IN PEDIATRIC ONCOLOGY AND MUSIC AS A HEALTH PROMOTER: MEANINGS FOR PROFESSIONALS}

\section{DESEMPEÑO EN ONCOLOGÍA PEDIÁTRICA Y LA MÚSICA COMO PROMOTORA DE SALUD: SIGNIFICADOS PARA LOS PROFESIONALES}

Jeane Barros de Souza ${ }^{1}$, Simone dos Santos Pereira Barbosa ${ }^{2}$, Emanuelly Luize Martins ${ }^{3}$, Débora Ceccatto ${ }^{4}$, Kelly Cristina de Prado Pilger $^{5}$, Angélica Zanettini ${ }^{6}$

\section{RESUMO}

Objetivo: Compreender os significados para os profissionais em trabalhar na oncologia pediátrica e em utilizar a música como promotora de saúde no ambiente hospitalar. Método: Estudo descritivo, exploratório, de abordagem qualitativa, fundamentado nos pressupostos teóricos do Interacionismo Simbólico, realizado com 10 profissionais do setor da oncologia pediátrica do maior hospital regional infantil do Oeste catarinense. A coleta de dados ocorreu, por meio de uma entrevista semiestruturada com cada profissional. Os dados foram analisados conforme análise de conteúdo, direcionada para a categoria temática. Resultados: Trabalhar na oncologia pediátrica mostrou demandar dedicação dos profissionais, além da formação do vínculo para haver confiança e apoio entre equipe de cuidado, indivíduos hospitalizados e familiares. É um setor com possibilidades para promover saúde, por meio do conforto, orientações e pelas diversas ações que proporcionam distração, como a música. Conclusão: Atuar na pediatria oncológica é gratificante, com aprendizado constante, sendo que a música é um instrumento para promover saúde no setor, pois oportuniza o relaxamento, distração, reflexões, esperança e ânimo para aqueles que a ouvem, possibilitando humanização na assistência em saúde no ambiente hospitalar.

Descritores: Oncologia; Profissionais da Saúde; Promoção da Saúde; Música.

\section{ABSTRACT}

Objective: to understand how professionals feel about working in pediatric oncology and using music as a health promoter in the hospital environment. Method: a descriptive, exploratory, and qualitative study, based on the theoretical assumptions of Symbolic Interactionism, carried out with 10 professionals in the pediatric oncology sector of the largest regional children's hospital in Western Santa Catarina. Data collection took place through a semi-structured interview with each professional. The data were analyzed according to content analysis, directed to each category. Results: working in pediatric oncology has shown to demand dedication from professionals, in addition to creating a bond of trust and support between the care team members, the hospitalized individuals and their family members. It is a sector with possibilities to promote health through comfort, guidance and several actions that provide distraction, such as music. Conclusion: acting in oncology pediatrics is rewarding and offers constant learning. Furthermore, music turns out to be an instrument to promote health in the sector, as it allows relaxation, distraction, reflections, hope, and encouragement for listeners, and enables humanization in health care in the hospital environment.

Descriptors: Oncology; Health professionals; Health promotion; Music.

\section{RESUMEN}

Objetivo: comprender el significado para los profesionales en el trabajo en oncología pediátrica y en el uso de la música como promotora de salud en el ámbito hospitalario. Método: estudio descriptivo, exploratorio con abordaje cualitativo, basado en los supuestos teóricos del Interaccionismo Simbólico, realizado con 10 profesionales del sector de oncología pediátrica del mayor hospital regional infantil del Occidente de Santa Catarina. La recolección de datos se realizó a través de una entrevista semiestructurada con cada profesional. Los datos fueron analizados según el análisis de contenido, dirigido a la categoría temática. Resultados: trabajar en oncología pediátrica ha demostrado exigir dedicación de los profesionales, además de formar un vínculo para tener confianza y apoyo entre el equipo de atención, las personas hospitalizadas y los familiares. Es un sector con posibilidades de promover salud a través del confort, la orientación y las diversas acciones que brindan distracción, como la música. Conclusión: actuar en pediatría oncológica es gratificante, con aprendizaje constante, y la música es un instrumento para promover salud en el sector, ya que permite la relajación, la distracción, la reflexión, la esperanza y el estímulo para quienes la escuchan, posibilitando la humanización en el cuidado de la salud en el entorno hospitalario.

Descriptores: Oncología; Profesionales de la salud; Promoción de la salud; Música.

${ }^{1}$ Pós-doutorado em Enfermagem. Docente do curso de graduação em Enfermagem da Universidade Federal da Fronteira Sul Sul - UFFS, campus Chapecó- SC, Brasil. ${ }^{2}$ Discente da UFFS, campus Chapecó- SC, Brasil. ${ }^{3}$ Mestranda em Enfermagem na UFSC, Florianópolis-SC, Brasil. ${ }^{4}$ Discente da UFFS, campus Chapecó- SC, Brasil. ${ }^{5}$ Discente da UFFS, campus Chapecó- SC, Brasil. ${ }^{6}$ Enfermeira. Mestranda no Programa de Pós-Graduação em Ciências da Saúde da Unochapecó. Docente substituta do curso de graduação em Enfermagem da UFFS, campus Chapecó- SC, Brasil. 


\section{INTRODUÇÃO}

O câncer corresponde a um conjunto de doenças que ocasionam o desenvolvimento incontrolável de células anormais, podendo se desenvolver em qualquer lugar do organismo humano. Possui elevada incidência, sendo a primeira causa de morte entre crianças e adolescentes, de um a 19 anos de idade ${ }^{(1)}$. Os tipos de câncer que, geralmente, acometem esse público afetam o sistema sanguíneo e tecido de sustentação, sendo que os que mais comumente se apresentam são as leucemias e linfomas, seguidos por tumores cerebrais e outros tipos que afetam o sistema nervoso central ${ }^{(2)}$.

Na maioria dos casos, o tratamento iniciase, tardiamente, em razão do diagnóstico tardio, ou outras variáveis que dificultam o rastreamento precoce da doença, como dificuldade no acesso aos serviços e tecnologias( ${ }^{(3)}$. Na etapa de diagnóstico e posterior tratamento, inicia-se a vivência da hospitalização para crianças, necessitando de internações recorrentes e, por vezes, prolongadas, na unidade oncológica pediátrica.

A assistência ofertada pelos profissionais da saúde às crianças em tratamento oncológico torna-se um cuidado diferenciado, pois exige que os procedimentos e as situações sejam avaliadas e desenvolvidas com maior cautela e delicadeza, pois trata-se de um público vulnerável em consequência da nova condição de saúde e de todas as mudanças que a doença acarreta ${ }^{(4)}$. Além disso, é necessário o entendimento que o processo de hospitalização e o tratamento reestruturam a vida e a rotina das crianças, afastando-as de seus familiares, do seu lar, da escola, dos brinquedos e da liberdade fora do hospital. Somado a isso, ainda há os efeitos colaterais das medicações que causam náuseas, cansaço, inapetência, entre outros ${ }^{(3)}$.

A aproximação e formação do vínculo dos profissionais com as crianças, no setor oncológico, requer estratégias que envolvam brincadeiras, diversão e ludicidade, para que haja uma relação de confiança e o trabalho seja desenvolvido sem estresse para ambos os $\operatorname{lados}^{(4)}$. A utilização do lúdico torna-se uma importante ferramenta para reduzir os efeitos negativos da hospitalização, o que potencializa a adaptação dos indivíduos ao ambiente hospitalar, favorecendo a descontração, a formação de um lugar mais agradável e alegre ${ }^{(5)}$, promovendo saúde no ambiente hospitalar.

A Carta de Ottawa traz um dos primeiros conceitos amplos de promoção da saúde, considerando-a como o processo de capacitar os indivíduos e coletividades para atuação no aprimoramento da sua qualidade de vida. A saúde é vista como um conceito positivo, apresentando cinco campos de ação para a promoção da saúde: políticas públicas saudáveis, ambientes favoráveis à saúde, ação comunitária, habilidades pessoais e reorientação dos serviços de saúde ${ }^{(6)}$. No âmbito hospitalar, uma das estratégias para promover saúde é a música, que tem se desvelado como uma relevante tecnologia de cuidado em Enfermagem por abranger o indivíduo em seu físico, psicológico, social e espiritual, proporcionando momentos de tranquilidade, conforto e lazer, sendo um meio facilitador de comunicação entre os profissionais e indivíduo hospitalizado ${ }^{(7-8)}$.

A música no ambiente hospitalar, sendo empregada como uma ferramenta lúdica e de promoção da saúde, promove às crianças hospitalizadas sensações de tranquilidade, paz e descontração, possibilitando sua sensibilização quanto às letras e sons emitidos, por meio das canções. Ainda, permite que as crianças viagem, por meio de sua imaginação, desenvolvendo sua criatividade e ajudando-as a fugir de seus medos $^{(9)}$.

Porém, ainda existem fragilidades quanto a evidências científicas no ato de promover saúde no ambiente hospitalar. Nesse cenário, docentes e discentes de um curso de graduação em Enfermagem, de uma universidade pública do Sul do Brasil, ao evidenciar escassas atividades lúdicas no hospital pediátrico, decidiram organizar um programa de extensão, com o objetivo de promover momentos lúdicos aos indivíduos hospitalizados, por meio da música. Assim, em 2018, nasceu o programa de extensão Musicagem.

O programa de extensão envolve intervenção musical semanal para as crianças, bem como para seus familiares/acompanhantes e profissionais que atuam no setor oncológico. A partir dos resultados exitosos, a equipe do programa organizou um projeto de pesquisa, a fim de fortalecer evidências científicas sobre a utilização da música e seus benefícios para promoção da saúde no ambiente hospitalar, em busca da assistência humanizada e integral. A partir de então, despontou a questão norteadora do estudo: Quais os significados de trabalhar na oncologia pediátrica e de utilizar a música como promotora de saúde no ambiente hospitalar?

No cuidado em saúde, durante o processo de hospitalização, se estabelece vínculo entre os profissionais, as crianças e seus familiares, sendo 
relevante considerar os significados que emergem nessa interação relacional. Diante do exposto, optou-se em respaldar este estudo aos pressupostos teóricos do Interacionismo Simbólico, pois o profissional ao assistir uma criança hospitalizada estabelece interações afetivas e simbólicas, sendo um fenômeno social. A partir do agir simbólico, os indivíduos criam e usam símbolos para interagir com o mundo, sendo que sem esses símbolos, não seria possível se relacionar com outras pessoas ${ }^{(10)}$. Assim, o estudo objetivou compreender os significados de trabalhar na oncologia pediátrica e de utilizar a música como promotora de saúde no ambiente hospitalar.

\section{MÉTODO}

Trata-se de um estudo descritivo, exploratório, de abordagem qualitativa, fundamentado nos pressupostos teóricos do Interacionismo Simbólico, que foi pensado, inicialmente, por George Herbert Mead, sociólogo clássico e, posteriormente, descrito por Herbert Blumer, que aponta a relação dos significados de determinadas ações, das interações dos indivíduos, dos grupos e das linguagens ${ }^{(8)}$.

Este estudo é oriundo de um projeto de pesquisa matricial, de uma universidade pública do Sul do Brasil. Contou-se com a participação de 10 profissionais que atuavam no setor da oncologia, do maior hospital público pediátrico do Oeste catarinense. Como critérios de inclusão, foram considerados os profissionais que atuavam no setor da oncologia pediátrica e que já haviam participado da intervenção musical do programa de extensão Musicagem no ambiente hospitalar. Como critérios de exclusão, os profissionais que estavam em licença e que atuavam na oncologia pediátrica há menos de dois meses.

Essa intervenção musical é realizada semanalmente no hospital pediátrico. Para tanto, seis estudantes e duas docentes da área da Enfermagem cantam, voluntariamente, para as crianças hospitalizadas, seus familiares e profissionais do setor da oncologia, sendo acompanhados por violão e violino. O repertório musical envolve letras que abordam temáticas sobre amor, família, amizade, vida e esperança. Com a devida autorização das crianças hospitalizadas e de suas famílias, o grupo adentra nos quartos e realiza intervenção musical, escolhendo músicas, conforme a necessidade de cada um, promovendo saúde no ambiente hospitalar.
Para compreender os significados de trabalhar na oncologia pediátrica e do uso da música para promover saúde, utilizou-se como meio de coleta de dados a entrevista semiestruturada, contando com o apoio de um roteiro de questões semiestruturadas, envolvendo diversas temáticas: trabalho no setor oncológico, as vivências dentro e fora do hospital, compreensão sobre processo saúde-doença, possibilidades de promoção da saúde no hospital, os significados do uso da música como uma ferramenta para promover saúde e as sensações despertadas pela intervenção musical.

A coleta dos dados foi realizada no segundo semestre de 2019, após a realização da intervenção musical no hospital. A entrevista foi realizada no espaço hospitalar, em um local reservado que estivesse somente o profissional e o pesquisador, de acordo com a escolha do participante. No início da entrevista, foi apresentado o Termo de Consentimento Livre e Esclarecido (TCLE) e somente após assinatura e concordância, realizaram-se as entrevistas que foram gravadas por meio de smartphone.

Para a análise e interpretação dos dados, utilizou-se a análise de conteúdo na modalidade temática, proposta por Minayo ${ }^{(11)}$. Nessa modalidade, trabalha-se com a frequência de determinado objeto analisado, apresentando etapas como a pré-análise, que inclui uma leitura flutuante, identificando as falas, em seguida a codificação dos dados, trazendo unidades de significados, a análise temática, e por fim, uma categorização para atender ao objetivo do estudo.

Para manter o anonimato dos participantes, utilizou-se o nome de árvores para denominá-los, na simbologia de que, na assistência prestada no setor da oncologia, os profissionais vão se relacionando com as crianças e seus familiares, significando as raízes da árvore. A partir de então, tal relacionamento vai se fortalecendo e crescendo, mediante as internações constantes das crianças, assim como o caule da árvore, que cresce, despontando as folhas e os frutos, por meio do vínculo que se constrói nessa interação. Ressalta-se que a pesquisa respeitou os aspectos éticos, conforme a Resolução no 466/2012 e iniciou somente após aprovação no Comitê de Ética em Pesquisa, sob o parecer de no 3.324.427.

\section{RESULTADOS E DISCUSSÃO}

Participaram do estudo 10 profissionais do setor da oncologia pediátrica, com idades entre 23 e 56 anos, sendo oito do sexo feminino e dois do 
sexo masculino. Os participantes eram de diferentes profissões: cinco técnicos de Enfermagem, duas enfermeiras, uma médica, uma psicóloga e uma copeira. O tempo de atuação no setor variou de cinco a 24 meses.

Após a análise e exploração dos dados, elencaram-se três categorias, a saber: 1) Significados do trabalho na oncologia pediátrica; 2) Possibilidades de promover saúde das crianças e de seus familiares no espaço hospitalar; 3) Significados da música no hospital.

\section{Significados do trabalho na oncologia pediátrica}

A oncologia apresenta aspectos diferentes das demais unidades hospitalares. Na oncologia pediátrica, o cuidado holístico se intensifica, pois além de prestar assistência às crianças no processo de hospitalização, também é necessário cuidar de seus familiares e presenciar situações delicadas $^{(4)}$. Nesse sentido, são diversas as reações, maneiras e significados que interferem como os profissionais lidam com o trabalho nesse ambiente. Para alguns, o setor oncológico repercute na significação de um local interessante de atuação, o qual proporciona satisfação, sendo gratificante por apresentar resultados positivos na assistência e devolutiva dos indivíduos hospitalizados e de seus familiares ${ }^{(12)}$, conforme apontaram:

"[...] é muito bom." (Cerejeira)

"É muito gratificante porque a gente vê o carinho deles (crianças e familiares). Então, o agradecimento deles faz valer a pena e faz a gente pensar que está seguindo o rumo certo." (Laranjeira)

A satisfação de atuar em algo que aprecia, promove ao profissional realização pessoal e prazer em desenvolver tais atividades, o que contribui para resultados positivos e para o bemestar da equipe, como também dos indivíduos hospitalizados e familiares ${ }^{(13)}$. Isso se faz importante, principalmente na oncologia pediátrica, onde os profissionais compreendem a necessidade de atuar com sensibilidade, comprometimento e responsabilidade na assistência à saúde:

"Pra trabalhar na oncologia pediátrica, é preciso ter amor, paixão pelo que faz e também comprometimento [...]" (Pau-Brasil)

$O$ cuidado integral de crianças hospitalizadas vai além das técnicas, exigindo do profissional um olhar peculiar, que os inclui como sujeitos ativos no processo de cuidar, fortalecendo e facilitando a comunicação e relacionamento entre profissional-indivíduo hospitalizadofamiliares ${ }^{(14)}$. A partir do vínculo formado, o profissional compreenderá as particularidades, necessidades e anseios de todos que necessitam de cuidados, desenvolvendo estratégias e ações que irão contribuir em todo o processo de hospitalização( ${ }^{(15)}$.

Dentre as atividades realizadas na assistência, estão as educativas, que envolvem as orientações para proporcionar um período de hospitalização com melhor qualidade, a qual o profissional também percebe a necessidade de estar preparado ${ }^{(16)}$, como evidenciado pelos participantes do estudo:

"A gente precisa passar confiança, carinho, amor pelas crianças e também disciplina porque eles (crianças e familiares) tem que entender que, infelizmente, estão num tratamento e precisam seguir bem certinho." (Oliveira)

"Na oncologia tem que trabalhar bastante, porque precisa explicar tudinho, qual medicação fez, para que serve, quando retornará outra medicação, é sempre bom explicar bem direitinho, todas ações têm que ser bem orientadas."(Araucária)

Mas atuar na oncologia, também é algo desafiador, porque desperta significados, emergindo sentimentos que abalam o psicológico dos profissionais que desenvolvem a empatia ao colocar-se no lugar daquelas crianças e familiares:

"É difícil porque todos os dias a gente se depara com o sofrimento das crianças e dos pais (...) nosso psicológico, às vezes, fica bem abalado porque a gente se coloca no lugar deles." (Ipê)

"[...]eu, como mãe, às vezes me coloco no lugar. É difícil [...] a gente tem que trabalhar bastante o emocional, no meu caso, eu sou mãe de uma criança de 5 anos, uma faixa etária dos que internam bastante aqui." (Cerejeira)

"No começo não foi muito fácil... me lembrava da minha mãe que tinha câncer, que faleceu, foi bem complicado no começo."(Cedro)

"[...] as vezes a gente se pega em situações no lado emocional, que a gente tem que dar aquela segurada e manter o foco e ser forte[...]."( Limoeiro)

Os profissionais lidam com situações, durante o processo de hospitalização, ao acompanhar toda a sequência realizada da prestação da assistência, observando momentos de sofrimento, angústia, incertezas. A vivência hospitalar para os profissionais pode gerar sentimentos, seja de sofrimento, de alegria, de apreensão, de esperança, emergindo significações 
pessoais e emocionais ${ }^{(17)}$. Nesse sentido, muitos relatam ter uma mistura de sentimentos, podendo estar alegres e, em outro momento, apresentar tristeza:

"[...] a gente se apega às crianças e acaba sofrendo junto, ficando feliz junto, é tudo um misto de sentimento." (Limoeiro)

"[...] a gente se apega, a gente sofre junto e se alegra junto [...] tem certas coisas que acontecem com as crianças que a gente não entende porque a gente espera que elas tenham uma vida inteira para viver, não é?" (Araucária)

"É um misto de sentimentos na verdade, porque a gente tem que cuidar, mas ao mesmo tempo a gente acaba se apegando." (Ipê)

"[...]a gente vê o carinho das crianças, eles se apegam na gente, e a gente se apega neles [...]" (Pau-Brasil)

Os profissionais podem se deparar com situações em que não conseguem lidar com os sentimentos, necessitando de apoio psicológico ou de trabalhar em equipe sobre os sentimentos despertados, a fim de desabafar e compartilhar tristezas e satisfações, o que contribui para o fortalecimento das interações entre a equipe e relações da vida do profissional ${ }^{(17-18)}$. Mas, além da relação com as crianças, os profissionais também lidam com a comunicação com os familiares. Os profissionais devem se vincular aos familiares, envolvendo o cuidado, assistindo-os de forma humanizada, acolhedora, o que gera confiança, contribuindo na recuperação do indivíduo hospitalizado ${ }^{(15)}$ :

"[...]a gente tem que ser forte pela gente, tem que ser forte pelos familiares e tem que ser forte também pras crianças." (Pau-Brasil)

"[...]a gente não cuida só do paciente, a gente cuida as vezes bem mais de um familiar, porque as vezes é um diagnóstico novo, a gente tem crianças que internam pra investigar e acaba fechando laudo, a gente tem o amparo das psicólogas, das nutricionistas, mas o convívio maior que ele tem é com a Enfermagem, então, qualquer coisinha que dá, eles chamam o pessoal da Enfermagem[...]" (Jacarandá)

A Enfermagem tem suma importância na assistência à saúde ao indivíduo hospitalizado. 0 enfermeiro tem maior proximidade no cuidado, seja com o indivíduo em sua integralidade, quanto para com seus familiares que costumam depositar confiança e vínculo com os profissionais de Enfermagem. Dentre as atividades que são bem executadas da Enfermagem e tornam-se potencialidades da profissão é a criação e manutenção do vínculo com os indivíduos e seus familiares, facilitador da assistência à saúde, tendo uma boa comunicação com os envolvidos, liderança e trabalho em equipe ${ }^{(19)}$.

O profissional, ao cuidar das crianças hospitalizadas e de seus familiares significa essa assistência com a simbologia de ser forte para lidar com as situações que envolvem a oncologia pediátrica, remetendo ainda ao sentimento de empatia, ao colocar-se no lugar das crianças e familiares em tratamento oncológico. Portanto, significa que esse cuidar relaciona-se às interações sociais que vão se estabelecendo, durante a hospitalização, pois, de acordo com o Interacionismo Simbólico, é a partir do processo de interação que os indivíduos formam os significados e agem em relação às outras pessoas e às coisas que os cercam ${ }^{(10)}$.

Assim, fica evidente a necessidade de um contínuo processo de capacitações e vivências, para que os profissionais possam aprimorar a assistência ao cuidado, seja em técnicas manuais, como também na comunicação com os indivíduos hospitalizados, familiares e equipe ${ }^{(16,18)}$. Dentre as formas de proporcionar o cuidado e a saúde de maneira ampla, destacam-se ações que podem promover a saúde nesse ambiente.

\section{Possibilidades de promover saúde das crianças e de seus familiares no espaço hospitalar}

A promoção em saúde surge como uma ferramenta para a melhoria da qualidade de vida do indivíduo hospitalizado, visando à integralidade no cuidado, considerando seu modo de vida e cultura. Dessa forma, promover a saúde na área hospitalar é de extrema importância, visto que o processo de hospitalização é uma mudança abrupta, ainda mais para as crianças, pois modifica a sua rotina, suas relações de amizade e seu espaço de lazer ${ }^{(9)}$.

Nessa perspectiva, é de grande relevância quando a equipe multiprofissional, especialmente a de Enfermagem, busca integralizar o cuidado, ao acolher o indivíduo hospitalizado e a família, buscando criar um vínculo para obter-se confiança e facilitar a efetivação da assistência em saúde, e ainda, por meio da escuta e atenção, orientar e auxiliar na melhoria do processo de hospitalização ${ }^{(3)}$ :

"Pelo nosso trabalho é possível promover saúde, porque geralmente a gente já vem com a parte só do tratamento, do cuidado em si, né? Então, normalmente as crianças que estão aqui é porque já tem alguma enfermidade, alguma 
doença, alguma coisa, então, a gente também pode orientar, aconselhar os familiares." (PauBrasil)

"[...] incentivando, ajudando sempre que eu posso e orientando as crianças e seus familiares a terem uma vida melhor aqui no hospital." (Jacarandá)

Os familiares também sofrem com a doença e com o processo de hospitalização, pois junto do problema de saúde há o impacto emocional, os medos e os anseios, além do desgaste e desequilíbrio mental ${ }^{(20)}$. Todo esse contexto, exige dos profissionais a oferta de apoio e de suporte para que possa promover um ambiente saudável e menos traumático, tanto para o indivíduo hospitalizado quanto para seu familiar, tendo em vista o processo de interação social que se estabelece durante a hospitalização:

"Acho importante dar suporte e buscar orientar as crianças e sempre conversar com a mãe e ou o pai que os acompanham." (Limoeiro)

"Também importante passar confiança para a mãe... A mãe precisa estar segura para passar segurança para a criança." (Cerejeira)

Ao resgatar os pressupostos do Interacionismo Simbólico, fica evidente que o profissional, ao cuidar da criança em tratamento oncológico e do seu familiar, constrói significados nessa interação. A partir dessas interações e dos acontecimentos da vida, durante o tratamento oncológico, surgem as significações e o processo de comportamento da mente, suscitando um espaço para o self se desenvolver e formar símbolos que são absorvidos e internalizados no self de cada ser ${ }^{(10)}$. Assim, os profissionais passam a cuidar das crianças e de seus familiares, conforme as suas necessidades estabelecidas, durante $\mathrm{o}$ ato de cuidar, buscando orientá-los numa relação de confiança e segurança.

Ademais, para além da prática medicamentosa e assistencial, o conforto é uma das formas do cuidado em Enfermagem que deve ser aplicado, durante 0 processo de hospitalização, tendo em vista que a criança sofre com o tratamento contínuo e intensivo, assim como aqueles que a acompanham ${ }^{(21)}$ :

"Oferecer o que for possível aqui no hospital para o conforto das crianças e de seus pais... até oferecer um cobertor a mais, tentar ver na cozinha outra alimentação que a criança goste e possa comer... são pequenos cuidados, mas que podem trazer mais conforto." (Cerejeira)

Ao cuidar de crianças dentro do serviço de saúde, é necessário que se observe a individualidade de cada uma, a fim de respeitar seu desenvolvimento biopsicossocial ${ }^{(21)}$. Para tanto, sugere-se utilizar a ludicidade e interação, que auxiliam à criança na diminuição do estresse causado pelo tratamento, a aproxima do profissional, diminui o medo e também torna o local de trabalho mais ameno ${ }^{(5)}$ :

"Ter bastante dinâmica, atividades interativas, não colocar as crianças e as famílias só dentro de um quarto e tratar com medicação, acho que tem que ter o tratamento psicológico para eles também." (Pau-Brasil)

"Com carinho, com amor, com abraços [...]" (Cedro)

A utilização do brincar como forma de apresentação à criança hospitalizada é significativo, porém seu uso durante a prática do cuidado, adequando a parte técnica, faz com que haja maior espontaneidade (22). Cabe destacar que, no ambiente lúdico está inserido também o uso da música, que auxilia na diminuição da tensão e ansiedade, proporcionando estímulos intelectuais, entre outros benefícios. Além do mais, a aplicação da música conforme a preferência do indivíduo hospitalizado conduz à diversão e ao sorriso, melhorando o conforto do cuidado $^{(23)}$.

Os profissionais, em especial a equipe de Enfermagem, compreendem a necessidade de um cuidado integral, para além do modelo biomédico, que contribua não só com a busca da cura da doença, mas que traga qualidade de vida àqueles que estão nesse processo de hospitalização e acompanhamento. Para tanto, buscam apoio em atividades que possam proporcionar maior qualidade e significação no período de hospitalização, empregando tecnologias para promover a saúde, como a utilização da música.

\section{Significados da música no hospital}

$\mathrm{Na}$ oncologia pediátrica as crianças são submetidas a mudanças no seu cotidiano, o que aumenta sua vulnerabilidade, visto que ficam afastadas de seu grupo de convívio e restritas a ficarem, parte do tempo, isoladas em seu leito ${ }^{(20)}$. Tendo em vista essas mudanças, é de extrema importância que haja uma relação saudável entre profissional e a criança hospitalizada, bem como qualidade no atendimento, que preconiza ser um cuidado humanizado e empático, respeitando suas limitações e sentimentos num ambiente acolhedor, em busca do desenvolvimento saudável.

Dessa forma, considera-se o ambiente como influenciador da recuperação. Nesse 
aspecto, a música se desponta como uma possibilidade de promover a saúde no ambiente hospitalar, pois influencia o processo de ambientação, auxiliando na manutenção da saúde mental dos que necessitam de cuidados e dos profissionais. Como atividade complementar, ela desperta sensações de felicidade, de descontração, de relaxamento e de leveza (24), conforme apontado pelos participantes do estudo:

"[...] a música nos traz conforto e animação para seguir o plantão, porque deixa o ambiente mais leve." (Cerejeira)

"É um momento bacana, que as pessoas distraem um pouquinho." (Araucária)

"[...] é um momento que a gente consegue distrair, esquecer um pouco de toda essa rotina do hospital, consegue relaxar. E também para as crianças e familiares porque dá para ver que eles ficam bem felizes, quando pessoal da música chega." (Cedro).

A escolha do repertório musical é relevante e significativa, pois a hospitalização é um momento de vulnerabilidade, tanto das crianças como de seus familiares. As músicas que transmitem mensagens de esperança e positividade são escolhas satisfatórias, levando em conta o ânimo e a disposição da criança e de seu familiar, para que a letra e a melodia sejam apropriadas para o momento pelo qual estejam vivenciando ${ }^{(25)}$, como é observado nos relatos de Laranjeira e Ipê:

"As músicas tem umas letras bonitas, que faz a gente refletir." (Laranjeira)

"Vocês tocam músicas muito boas e isso traz muitos significados e sentimento importantes, que às vezes encaixa exatamente ao momento que a pessoa está passando e traz esperança para seguir em frente." (Ipê)

Além disso, os profissionais também abordaram que a música desencadeia felicidade, estímulo, conforto e lazer para as crianças e para eles também:

"A música traz animação para as crianças, mais felicidade [...] um estímulo maior, mostra que a criança está ativa e alegra e é bom que nos alegra também." (Oliveira)

"A música traz lazer aqui no hospital e as crianças gostam muito [...] é muito importante para as crianças na oncologia e para nós também." (Seringueira)

"Quando a música chega aqui no hospital, traz conforto pra gente e para os que estão internados." (Ipê)
Em decorrência de 0 processo de hospitalização ser relacionado a sentimentos desagradáveis e sob intensa tensão, tanto os profissionais quanto os indivíduos hospitalizados e familiares se sobrecarregam com significados negativos, envolvidos num misto de sentimentos e insegurança, que podem trazer desânimo ${ }^{(9)}$. Por conta disso, é importante implementar atividades que ajudem a harmonizar o local, promovendo lazer, com momentos de felicidade e descontração, já que o ambiente é um grande influenciador na recuperação ${ }^{(18)}$ e no bom desempenho do trabalho.

A música é considerada um instrumento lúdico relevante para o desenvolvimento da criança, tanto da fala, quanto na construção de sua personalidade, além de interferir, significativamente, no seu emocional e no de todos que a rodeiam, trazendo consigo diversos sentimentos ${ }^{(9)}$. Para os participantes do estudo, a música suscita significações que auxiliam na promoção da saúde da criança hospitalizada e também dos profissionais que atuam no local:

"Eu acho que é um momento especial, tanto pra quem está trabalhando aqui, quanto pra quem está internado [..] essas atividades diferentes também proporciona a eles algum momento melhor, mais energizante." (Cerejeira)

"As vezes dá vontade de chorar dependendo o momento, a situação como esta aqui, de sorrir, de cantar junto de brincar, vários sentimentos [...]" (Jacarandá)

"A música ajuda a promover saúde porque deixa todo mundo feliz aqui e às vezes está no momento triste, está ali quietinho, e com a música a gente se alegra, as crianças dão risada, eles querem cantar, acho que tudo isso promove saúde, a criança fica feliz, e a saúde melhora." (Laranjeira)

"A música libera os hormônios da felicidade, trabalha melhor, circula o sangue melhor, as crianças ficam mais animadas, é uma ajuda que a Enfermagem tem pra avaliar como está a criança [...]" (Limoeiro).

A música está presente na vida dos seres humanos e influencia, diretamente, na oscilação de humor e na predisposição para a realização de tarefas, considerando que está relacionada com as dimensões biológicas, emocionais, espirituais e mentais de cada indivíduo ${ }^{(8)}$. Por conta disso, quando bem empregada, pode auxiliar na promoção e recuperação da saúde do indivíduo hospitalizado, além de motivar e contribuir para o aperfeiçoamento das práticas profissionais. 
No entanto, a música não atua somente para promover a saúde dos indivíduos hospitalizados. Ela também gera alegria, relaxamento e alívio sobre a carga de trabalho na atenção à saúde ${ }^{(25)}$, em destaque para os profissionais que atuam na oncologia pediátrica:

"A música dá uma alegria, dá uma energia para gente." (Oliveira)

"Alegria porque às vezes a gente está em um dia tenso, tudo acontece, fica triste, e a música alegra a gente, dá um up e esperança." (Limoeiro)

$\mathrm{Na}$ perspectiva do Interacionismo Simbólico, os profissionais ao assistir as crianças e seus familiares estão refletindo, sentindo, relacionando, interagindo, por meio do uso da música e de tantas outras estratégias, é o agir simbólico ${ }^{(10)}$. Nesse âmbito, a utilização da música é uma tecnologia de cuidado que auxilia no processo interacional e promove a saúde, pois de maneira delicada e significativa, ela transforma a energia e as emoções desagradáveis, por momentos de esperança e alegria no ambiente hospitalar.

\section{CONSIDERAÇÕES FINAIS}

Dentre as particularidades do tratamento do câncer infantil, destaca-se o processo de hospitalização, que significa uma mudança na rotina da criança, distanciamento do lar, dos brinquedos e de toda vida fora do hospital. Para os profissionais, a atuação no setor da oncologia significa confiança, contínuo crescimento, aprendizado, satisfação e reflexão. Mas também, durante o trabalho, o cuidado às crianças e aos seus familiares desperta significações que os afeta, ao partilhar suas vivências e sofrimentos, o que por vezes, os abala psicologicamente.

Para tornar suave e de melhor qualidade o período de hospitalização, os profissionais buscam desenvolver um processo interacional com as crianças e seus familiares, ofertando uma assistência de maneira lúdica, com estratégias para auxiliar no cuidado humanizado, como o emprego da música. Os profissionais que atuam na oncologia pediátrica acreditam que a música pode ser um instrumento para a promoção da saúde das crianças, familiares e deles próprios.

A música traz significados de aproximação, vínculo com a criança e sua família, renovação das energias do ambiente hospitalar, ressurgimento da esperança e da felicidade, contribuindo para amenizar os desafios da hospitalização pediátrica. Nessa perspectiva, torna-se necessário que os profissionais, em especial a Enfermagem, busquem possibilidades para propiciar momentos musicais no ambiente hospitalar, reconhecendo as significações que a música proporciona, sendo que, neste estudo, desvelou-se a relevância da sua utilização como uma tecnologia de cuidado, contribuindo na expansão do arcabouço dos meios de se prestar assistência à saúde.

Esta pesquisa repercute em contribuições quanto aos significados que envolvem o cuidado no setor da oncologia pediátrica, com inovação, ao considerar a música como instrumento de promoção da saúde. Como limitações do estudo aponta-se a falta de oportunidade de entrevistar todas as categorias de profissionais que atuam no setor da oncologia, já que esse local demanda uma equipe multiprofissional e compromissada. Sugere-se, como continuidade do estudo, uma abordagem da temática com diferentes profissionais que atuam no âmbito hospitalar, para além da oncologia pediátrica, a fim de ampliar as evidências científicas e, assim, instigar a outras instituições e setores, para que reconheçam a significância do uso da música como tecnologia de cuidado e possam também usufruir dos seus benefícios.

\section{REFERÊNCIAS}

1- Brasil. Ministério da saúde. Câncer infantojuvenil. Brasília: INCA; 2016. Disponível em: https://www.inca.gov.br/tipos-de-cancer/cancerinfantojuvenil

2- Fedorovsky JM, Cuervo LG, Luciani S. Pediatric cancer registries in Latin America: The case of Argentina's pediatric cancer registry. Rev Panam Salud Pública 2017;41:1-5. DOI: 10.26633/RPSP.2017.152

3- Silva CMM, Silva MPC, Ferreira DO, Amaral JB, Gonçalves JRL, Contim D. Significado do cuidar e seus sentimentos para equipe de enfermagem diante da criança em tratamento oncológico. Rev Enferm Atenção Saúde 2018;7(2): 83-94. DOI: 10.18554/reas.v7i2.2355

4- Teixeira MR, Sanhudo NF, Moura DCA, Bahia MTR. Processo de enfrentamento emocional da equipe de enfermagem no cuidado de crianças com câncer hospitalizadas. REUFSM 2019;8(2):263-75. DOI: 10.5902/2179769227319

5- Marques EP, Garcia TMB, Anders JC, Luz JH, Rocha PK, Souza S. Lúdico no cuidado à criança e ao adolescente com câncer: Perspectivas da equipe de enfermagem. Esc Anna Nery 2016;20(3):1-8. DOI: $\quad 10.5935 / 1414-$ $\underline{8145.20160073}$ 
6- World Health Organization (WHO). The Ottawa charter for health promotion. Ottawa: WHO; 1986.

7- Souza JB, Campagnoni JP, Barbosa SSP, Sauer AG, Zenenvicz LT, et al. Música no hospital: Promoção da saúde na oncologia. Rev Bras Promoç Saúde 2019;32:1-8. DOI: $10.5020 / 18061230.2019 .8920$

8- Cardoso AVM, Souza AAM, Silva PLN, Carvalho HLA, Alves ED, Aguiar Filho W. Cuidando com arte a promoção da saúde por meio da música. Rev Univ Vale Rio Verde 2016;14(1):714-35. DOI: 10.5892/ruvrd.v14i1.2531

9- Silva GH, Piovesan JC. Música e alegria: Uma prática humanizada para crianças hospitalizadas. Vivências 2020;16(30):127-44. DOI: $\underline{10.31512 / \text { vivencias.v16i30.146 }}$

10- Correa AS. Interacionismo simbólico raízes, críticas e perspectivas atuais. RBHCS. 2017 [citado em 20 fev 2020]; 9(17):1-25. Disponível em: https://dialnet.unirioja.es/servlet/articulo?codigo $=6737540$

11- Minayo, M. C. S. O desafio do conhecimento: Pesquisa qualitativa em saúde. 13a ed. São Paulo: Hucitec; 2013.

12- Bordignon M, Ferraz L, Beck CLC, Amestoy SC, Trindade LL. (In) satisfação dos profissionais de saúde no trabalho em oncologia. Rene 2015;16(3):398-406. DOI: 10.15253/2175$\underline{6783.2015000300013}$

13- Leite AF, Nogueira JAD. Fatores condicionantes de saúde relacionados ao trabalho de professores universitários da área de saúde: Uma revisão integrativa. Rev Bras Saúde Ocup. 2017;42:1-15. DOI: $10.1590 / 2317-6369000010116$

14- Caleffi CCF, Rocha PK, Anders JC, Souza AlJ, Burciaga VB, Serapião LS. Contribuição do brinquedo terapêutico estruturado em um modelo de cuidado de enfermagem para crianças hospitalizadas. Rev Gaúcha Enferm. 2016;37(2):18. DOI: $10.1590 / 1983-1447.2016 .02 .58131$

15- Santos SS, Alves ABS, Oliveira JC, Gomes A, Maia LFS. A ludoterapia como ferramenta na assistência humanizada de enfermagem. Rev Recien. 2017;7(21):30-40. DOI: 10.24276/rrecien2358-3088.2017.7.21.30-40

16- Pereira DMB, Bertoldi K, Roese A. Percepções dos profissionais de Enfermagem na assistência a crianças portadoras de câncer. Rev Enerm UFSM 2015;5(1):112-20. DOI: $10.5902 / 2179769213426$ 17- Silva AF, Issi HB, Motta MGC, Botene DZA. Cuidados paliativos em oncologia pediátrica: Percepções, saberes e práticas na perspectiva da equipe multiprofissional. Rev Gaúcha Enferm.
2015;36(2):56-62. DOI: $\quad \underline{10.1590 / 1983-}$ 1447.2015.02.46299

18- Monção GFR, Retlcena KO, Gomes MFP, Cardoso EMR, Fracolli LA. Situações vivenciadas pela equipe de Enfermagem de uma unidade Oncológica. Rev Bras Cancerol. 2019;65(1):1-6. DOI: $10.32635 / 2176-9745 . R B C .2019 v 65 n 1.325$

19- Weber ML, Vendruscolo C, Adamy EA, Trindade LL, Heidemann ITSB, Rosset D. Melhores práticas de Enfermagem: Potencialidades e desafios em um contexto assistencial. R Enferm Cent O Min. 2019;9(1):1-10. DOI: 10.19175/recom.v9i0.3504

20- Rocha ENT, Rocha RR. The treatment of hospitalized children. Journal of Specialist 2018 [cited by 28 mar 2020]; 2(2):1-21. Available from: http://journalofspecialist.com/jos/index.php/jos/ article/view/99/54

21- Neves JN, Mendes DRG, Santos WL. Enfermagem em oncologia pediátrica: Fatores de excelência na assistência integralizada. BCESA 2017 [citado em 17 mar 2020]. Disponível em: https://www.senaaires.com.br/wpcontent/uploads/2017/05/ENFERMAGEM-EMONCOLOGIA-PEDI\%C3\%81TRICA-FATORES-DEEXCEL\%C3\%8ANCIA-NA-ASSIST\%C3\%8ANCIAINTEGRALIZADA.pdf

22- Mitre RMA, Gomes R. A promoção do brincar no contexto da hospitalização infantil como ação de saúde. Ciênc Saúde Coletiva 2004;9(1):147-54. DOI: 10.1590/S1413-81232004000100015

23- Silva LAGP, Baran FDP, Mercês NNA. Música no cuidado de crianças e adolescentes: Revisão integrativa. Texto \& Contexto Enferm. 2016;25(4):1-10. DOI: 10.1590/0104$\underline{07072016001720015}$

24- Zanettini A, Souza JB, Franceschi VE, Finger D, Gomes A, Santos MS. Quem canta seus males espanta: Um relato de experiência sobre o uso da música como ferramenta de atuação na promoção da saúde da criança. Rev Min Enferm. 2015;19(4):1060-4. DOI: 10.5935/14152762.20150079

25-Claro LBL, Delvo VN, Valente LR. Percepções de pacientes e profissionais da saúde sobre as visitas musicais do programa de extensão "boa noite, bom dia huap". Rev. Conexão UEPG 2017;13(1):66-83. DOI: 10.5212/Rev.Conexao.v.13.i1.0005

Recebido em: 17/05/2020 Aprovado em: 20/08/2020 
Endereço de correspondência:

Jeane Barros de Souza

Rodovia SC 484 Km 02, Sala 311, Bairro Fronteira Sul, CEP:

89815899, Chapecó-SC.

E-mail: jeanebarros18@gmail.com 